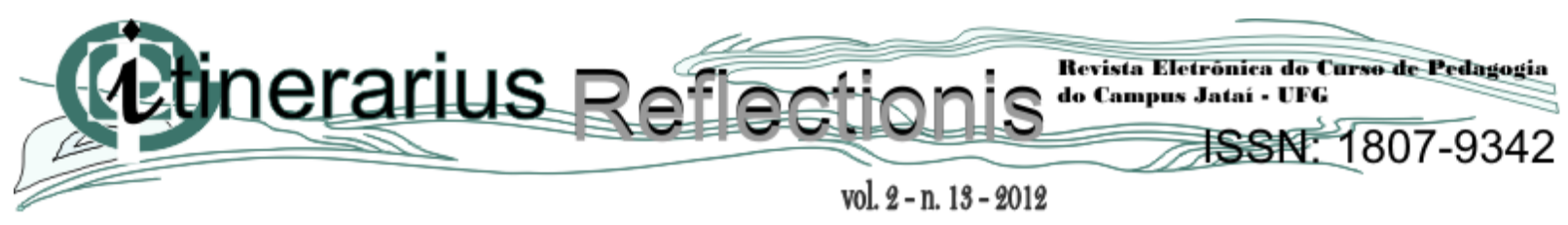

\title{
PERCEPÇÃO DOS ALUNOS QUANTO ÀS QUESTÕES ABORDADAS NA AVALIAÇÃO DO DOCENTE EM UMA INSTITUIÇÃO DE ENSINO SUPERIOR
}

Thaís Rocha Assis. Professora do Curso de Fisioterapia da Universidade Federal de Goiás, Campus Jataí. rochafisio@ hotmail.com

Christiane Ricaldoni Giviziez. Professora do Curso de Biomedicina da Universidade Federal de Goiás, Campus Jataí.

Graciele Paraguaia Silveira. Professora do Curso de Matemática da Universidade Federal de Goiás, Campus Jataí.

Marlene Andrade Martins. Professora do Curso de Enfermagem da Universidade Federal de Goiás, Campus Jataí. marlenianapower@ hotmail.com

Martha Ribeiro Bonilha Professora do Curso de Biomedicina da Universidade Federal de Goiás, Campus Jataí. marthabonilha@ @otmail.com

RESUMO: A avaliação sistemática da prática pedagógica dos professores no decorrer do ano letivo, realizada pelos alunos, é importante para o aprimoramento do ensino, pois esta avaliação permite ao professor investigar a própria prática, o que é essencial para qualificar a ação docente em direção a um ensino mais produtivo, mais adequado à realidade e mais humano. Na Universidade Federal de Goiás (UFG), os docentes são avaliados pelos discentes a cada final de semestre por meio de um instrumento de avaliação de desempenho didático. Neste contexto, este estudo teve como objetivo analisar a percepção dos alunos em relação às questões abordadas nesse instrumento de avaliação do docente pelo discente. Trata-se de um estudo qualitativo e descritivo realizado com discentes de diferentes cursos de graduação da UFG/Campus Jataí. Foi utilizado um questionário individual contendo perguntas abertas, elaborado com base no instrumento avaliativo dos docentes, utilizado na instituição. Os dados coletados foram organizados em 12 categorias gerais que corresponderam a cada uma das perguntas do questionário elaborado. Neste trabalho acreditamos que os alunos, de uma forma geral, entendem as questões do instrumento de avaliação da UFG. Em contato com as respostas obtidas no questionário aplicado, foi possível perceber que a contribuição do aluno é maior quando se utiliza questões abertas, pois elas não expressam somente notas, mas também 


\title{
Qbinerarius Refifoctionis 21 \\ vol. 2-n. 13-2012

expectativas quanto às atividades docentes. Outro aspecto observado foi a necessidade dos professores esclarecerem melhor aos alunos os itens do plano de ensino.

Palavras-chave: Instrumento de avaliação do docente. Percepção dos alunos. Educação superior.

\section{STUDENTS' PERCEPTION REGARDING THE ISSUES ADDRESSED TO TEACHERS' EVALUATION IN A HIGHER EDUCATION INSTITUTION}

\begin{abstract}
The systematic evaluation of the teachers' pedagogical practice in the course of the school year, performed by the students, is important for the teaching improvement, since this evaluation helps the teacher to investigate his/her own practice, which is essential to qualify the teachers' action towards a more productive teaching, more appropriate to reality and more human. At Universidade Federal de Goiás (UFG), the teachers are evaluated by the students at the end of every semester, using an educational performance evaluation instrument. Within this context, the objective of this study was to analyze the students' perception, regarding the issues addressed to the assessment tool mentioned. This qualitative, descriptive study was conducted with students of different undergraduate courses at UFG/ Campus Jataí. An individual open-ended questionnaire was used, created based on the evaluation tool, used at that institution. The collected data were organized into 12 general categories that corresponded to each of the items on the questionnaire. In this study, we believe that, in general, the students understand the questions contained on the UFG evaluation tool. By analyzing the answers obtained on the applied questionnaire, we noticed that students contribute in a better way when open-ended questions are used, as they do not express only the scores, but also the expectation towards the teachers 'activities. Another aspect observed was the need for better explanation, concerning to the Course Plan items.
\end{abstract}

Key-words: Teaching evaluation tool. Students' perception. Higher education.

\section{Introdução}

Desde a década de 70, as instituições de ensino superior têm buscado o autoconhecimento, principalmente nos aspectos político, administrativo e acadêmico. Nas Universidades, destaca-se a avaliação do docente, pois apesar de vários fatores influenciarem 
na qualidade do ensino, a maior responsabilidade recai sobre o professor (GRILLO, 1992; RAMOS; MORAES, 2000).

A avaliação é um processo complexo, dinâmico e requer habilidades para a atribuição de valores acerca do avaliado. Entretanto, a responsabilidade da avaliação transcende a pessoa do educando e do educador já que os responsáveis pelos resultados do processo, são os mesmos que participam direta ou indiretamente da implementação do ensino na estrutura organizacional (KURCGANT; CIAMPONE; FELLI, 2001).

A avaliação sistemática da prática pedagógica dos professores no decorrer do ano letivo, realizada pelos alunos, é importante para o aprimoramento do ensino e evidentemente, da melhoria da qualidade desta ação nas Instituições de Ensino Superior, pois esta avaliação permite ao professor investigar a própria prática, o que é essencial para qualificar a ação docente em direção a um ensino mais produtivo, mais adequado à realidade e mais humano (RAMOS; MORAES, 2000; SANTOS; LARO, 2007).

O objetivo da avaliação do professor pelo aluno não é punir o professor pelas falhas cometidas e demonstradas através dos resultados dos questionários. Para que possa ser alcançado o objetivo da aplicação desta metodologia, há necessidade de humildade, reflexão e autocrítica por parte do professor, buscando a melhoria do seu ensino. O que interessa é o feedback, para dar condições para que o professor possa crescer como pessoa e como profissional (STRASSBURG; MOREIRA, 2002).

Na Universidade Federal de Goiás (UFG), os docentes são avaliados pelos discentes a cada final de semestre por meio de um instrumento de avaliação de desempenho didático que segue a Resolução CONSUNI n 21/2009 e algumas diretrizes estabelecidas pela Comissão de Avaliação Institucional (CAVI/UFG). De acordo com a CAVI/UFG, esta avaliação é baseada nos pressupostos filosóficos, teóricos e metodológicos, assim como em princípios e valores que norteiam a atual avaliação institucional.

Ramos e Moraes (2000) criticam essa avaliação sistemática, uma vez que a participação dos professores é mínima neste processo e, além disso, os professores avaliados fazem reflexões superficiais dos resultados e, somente quando estes apresentam alguma distorção, fazem questionamentos sobre o instrumento de coleta de dados, e não mais do que isso. 


\section{C(tatinerarius Refiectionis:}

Alguns questionamentos são constantemente levantados entre os professores quando acontece ao final de cada semestre a Avaliação do Docente pelo Discente na UFG/Jataí. E um deles é "será que os alunos entendem com clareza as questões presentes no instrumento de avaliação?”.

Neste contexto, este estudo teve como objetivo analisar a percepção dos alunos em relação às questões abordadas no instrumento para a avaliação do docente pelo discente.

\section{Materiais e métodos}

O trabalho realizado trata-se de um estudo qualitativo e descritivo, realizado com discentes de diferentes cursos de graduação da Universidade Federal de Goiás - Campus Jataí.

Diferentemente da pesquisa quantitativa, a pesquisa qualitativa busca uma compreensão particular daquilo que estuda. Tal pesquisa não se preocupa com generalizações, princípios e leis, mas sim com a compreensão dos fenômenos estudados (MARTINS E BICUDO, 1994).

O estudo qualitativo e descritivo possibilita o desenvolvimento de um nível de análise em que se permite identificar as diferentes formas dos fenômenos, sua ordenação e classificação. Dá margem, também, à explicação das relações de causa e efeito dos fenômenos, ou seja, analisar o papel das variáveis que, de certa maneira, influencia ou causa o aparecimento dos fenômenos. É o tipo de estudo que permite ao pesquisador a obtenção de uma melhor compreensão do comportamento de diversos fatores e elementos que influenciam determinado fenômeno (MARTINS E BICUDO, 1994).

As principais características deste método são a imersão do pesquisador no contexto e a perspectiva interpretativa de condução da pesquisa (KAPLAN E DUCHON, 1988). Na pesquisa qualitativa, o pesquisador é um interpretador da realidade. É essencial que se estabeleça uma boa relação entre o sujeito e o pesquisador (BRADLEY, 1993).

\subsection{Os sujeitos}




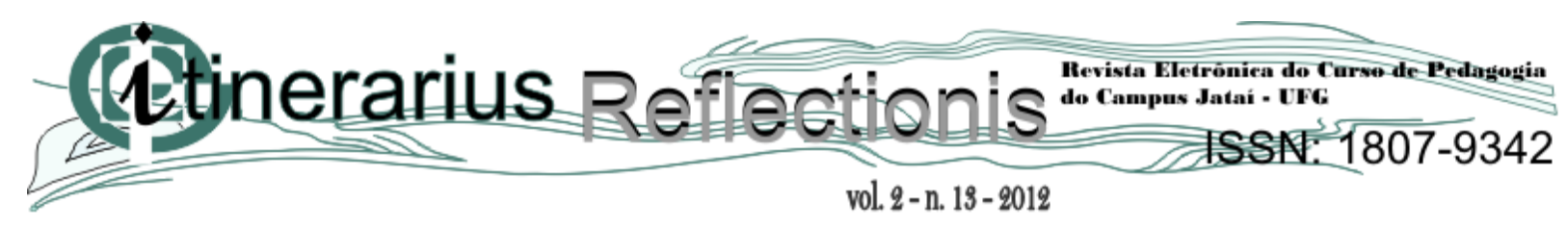

Participaram da pesquisa 26 discentes, escolhidos aleatoriamente, e que, de forma voluntária, dispuseram-se a colaborar com o estudo. Os cursos abrangidos foram Fisioterapia, Biomedicina, Enfermagem, Matemática, Física, Ciências Biológicas e Psicologia.

\subsection{O Instrumento}

Neste estudo foi utilizado um questionário individual contendo perguntas abertas, baseando-se no instrumento avaliativo dos docentes pelos discentes, utilizado na instituição.

$\mathrm{O}$ instrumento de avaliação do desempenho didático do docente pelo discente utilizado na UFG segue a Resolução CONSUNI no 21/2009 e algumas diretrizes estabelecidas pela Comissão de Avaliação Institucional (CAVI/UFG). Conforme Resolução aprovada, pelo CONSUNI, no dia 23 de março de 2001, em seu inciso IV do artigo $7^{\circ}$ e no inciso II do artigo $17^{\circ}$, ficou estabelecido que o “(...) processo de avaliação de estágio probatório deverá ser instruído com o resultado da avaliação do docente pelo corpo discente, a ser aplicado no mínimo uma vez a cada ano letivo, desde que tenham transcorrido três meses de efetivo exercício, devendo, para este fim, ser aplicado o formulário aprovado pela CAVI/UFG” e o “(...) desempenho acadêmico do docente, para fins de progressão horizontal, será avaliado pela $\mathrm{CAD}$ da Unidade por meio de desempenho didático do docente aferido anualmente pelo corpo discente, por meio de instrumento de avaliação aprovado pelo Conselho Diretor da Unidade e elaborado a partir de diretrizes estabelecidas pela CAVI/UFG".

Neste instrumento proposto pela CAVI/UFG, os itens avaliados são divididos em quatro categorias que avaliam frequência, aulas, avaliação da aprendizagem e atendimento ao estudante.

O questionário elaborado para este estudo foi composto pelas seguintes questões: Para você, as questões apresentadas na avaliação do professor pelo aluno são claras e de fácil entendimento?; Para você, o que é um professor que comparece regularmente às aulas sob sua responsabilidade?; Para você, o que é um professor que cumpre os horários de início e término das aulas?; Como você avalia se um professor segue e atinge os objetivos apresentados no Plano de Ensino da disciplina?; Em sua opinião, o que é o professor 


\section{(1tinerarius \\ vol. 2-n. 19-2012 \\ Revista Eletróniéa do Curse de Pedagogia

estabelecer relação entre a disciplina e o curso?; De que forma você avalia se o professor demonstra domínio dos conteúdos abordados e se os expõe didaticamente?; Para você, o que é um professor que mobiliza o interesse e estimula a participação dos estudantes nas aulas?;Como você julga se o professor incentiva a participação do estudante em atividades extraclasse?;Para você, o que significa o professor utilizar metodologias diversificadas e/ou instigadoras da aprendizagem?;Para você, o professor informa antecipadamente e com clareza os critérios de avaliação quando; Em sua opinião, quando o professor é coerente ao avaliar, abordando os conteúdos selecionados?;O que você considera o professor devolver regularmente as avaliações da aprendizagem após serem apreciadas e corrigidas?; O professor demonstra interesse pela compreensão, desempenho e aprendizado dos estudantes na disciplina quando ele:

O questionário foi aplicado no mês de outubro de 2011 e o sigilo e anonimato dos participantes foram mantidos e as respostas foram dadas na forma escrita.

1.3 Análise dos dados

A equipe de pesquisadores definiu as categorias a serem investigadas, antes do trabalho em campo. Após a coleta de dados, e com base nas análises das respostas de cada categoria foram formuladas categorias específicas buscando a classificação dos dados encontrados, segundo a metodologia proposta por Minayo et al (2000).

Neste sentido, as questões propostas no questionário constituíram as denominadas categorias gerais. Das respostas fornecidas pelos discentes emergiram as categorias específicas, dentro de cada categoria geral.

Foram estabelecidas 12 categorias gerais correspondentes a cada uma das perguntas do questionário elaborado. Essas categorias foram classificadas como segue: comparecimento do professor às aulas (categoria 1); cumprimento do horário de aula (categoria 2); alcance dos objetivos do plano de ensino da disciplina (categoria 3); estabelecimento de relação entre a disciplina e o curso (categoria 4); domínio dos conteúdos e didática ao repassá-los (categoria 5); mobiliza o interesse e estimula a participação (categoria 6); incentiva a participação dos alunos em atividades extraclasse (categoria 7); utiliza metodologias diversificadas e/ou instigadoras de aprendizagem (categoria 8); informa 
antecipadamente e de forma clara os critérios de avaliação (categoria 9); coerência ao avaliar (categoria 10); devolução de avaliações (categoria 11); interesse quanto à compreensão, desempenho e aprendizado dos alunos (categoria 12).

As categorias específicas foram apresentadas nos resultados.

\section{Resultados e Discussão}

Os resultados deste trabalho nos faz refletir sobre o tema avaliação como um processo sistemático que propicia ponderações sobre as práticas desenvolvidas nas instituições com o propósito de conhecer suas possibilidades e limitações (KURCGANT; CIAMPONE; FELLI, 2001).

Em algumas respostas dadas pelos alunos, observamos que eles entenderam a

\begin{tabular}{lll}
\hline Características dos estudantes & $\mathrm{n}$ & $\%$ \\
\hline Sexo & & \\
Masculino & 4 & 15,0 \\
Feminino & 22 & 85,0
\end{tabular}

pergunta como sendo uma afirmativa e, diante disso, eles não responderam a pergunta, e sim acrescentaram as expectativas em relação aos professores. Sendo assim, não será apresentado apenas o que os alunos entenderam de cada pergunta, mas também as suas expectativas quanto aos professores. 


\section{(titinerarius Reffectionis: = = 20

Período

$\begin{array}{lll}2^{\circ} & 13 & 50,0 \\ 6^{\circ} & 5 & 19,0 \\ 8^{\circ} & 8 & 31,0\end{array}$

Curso

$\begin{array}{lll}\text { Biomedicina } & 9 & 35,0 \\ \text { Ciências Biológicas } & 3 & 11,5 \\ \text { Enfermagem } & 4 & 15,3 \\ \text { Fisioterapia } & 3 & 11,5 \\ \text { Física } & 2 & 7,7 \\ \text { Matemática } & 2 & 7,7 \\ \text { Psicologia } & 3 & 11,5\end{array}$

A Tabela 1 mostra a caracterização dos estudantes entrevistados. A média de idade foi de $20,6( \pm 2,4)$ anos.

Tabela 1 - Características dos estudantes entrevistados $(n=26)$ nos diferentes cursos de graduação da Universidade Federal de Goiás, outubro/2011.

Quanto ao entendimento das questões abordadas no instrumento de avaliação do docente pelo discente, 22 alunos (85\%) afirmaram que os itens do instrumento de avaliação eram claros e de fácil entendimento e quatro (15\%) responderam que não entendiam os itens. Desses últimos, dois fizeram as seguintes observações:

“[...] não tem toda a clareza de palavras e frases, acho alguns argumentos complicados". (sujeito 11)

"Os termos usados são incomuns e muitas vezes confusos". (sujeito 16)

Dos 22 alunos que afirmaram que os itens eram claros e de fácil entendimento, três fizeram as observações que se seguem: 


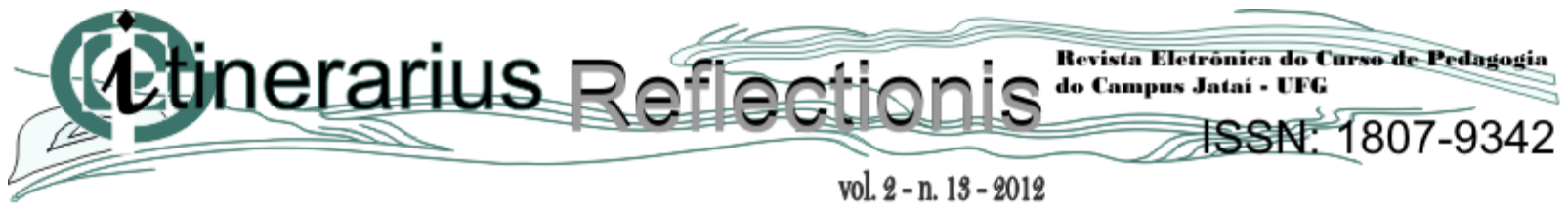

"Porém, algumas questões são um pouco de difícil compreensão, poucas deixa claro". (sujeito 26)

"Poderiam esclarecer mais certas perguntas, deixar um pouco mais específico". (sujeito 12)

“Algumas perguntas são claras e objetivas, outras não". (sujeito 17)

Portanto, apesar de a maioria dos alunos afirmarem que as questões do instrumento de avaliação do docente são de fácil entendimento, alguns alunos sugerem a necessidade de questões mais objetivas e claras.

Conforme já mencionado, foram elaboradas 12 categorias gerais. A partir destas categorias, surgiram várias categorias específicas e a Figura 1 apresenta as categorias específicas mais frequentes dentro de cada categoria geral.

Na pergunta do questionário que se referiu ao comparecimento do professor às aulas (categoria 1), a maioria dos estudantes (12) entendeu que o professor que comparece regularmente às aulas é aquele que cumpre a carga horária e falta somente em caso de necessidade avisando antecipadamente. Somente dois alunos (sujeitos 5 e 26) responderam sobre a pontualidade do professor e não sobre sua frequência às aulas.

Na pergunta sobre o cumprimento do horário de aula (categoria 2), a maioria dos alunos (12) escreveu que o professor pontual é aquele que inicia e finaliza as aulas no horário

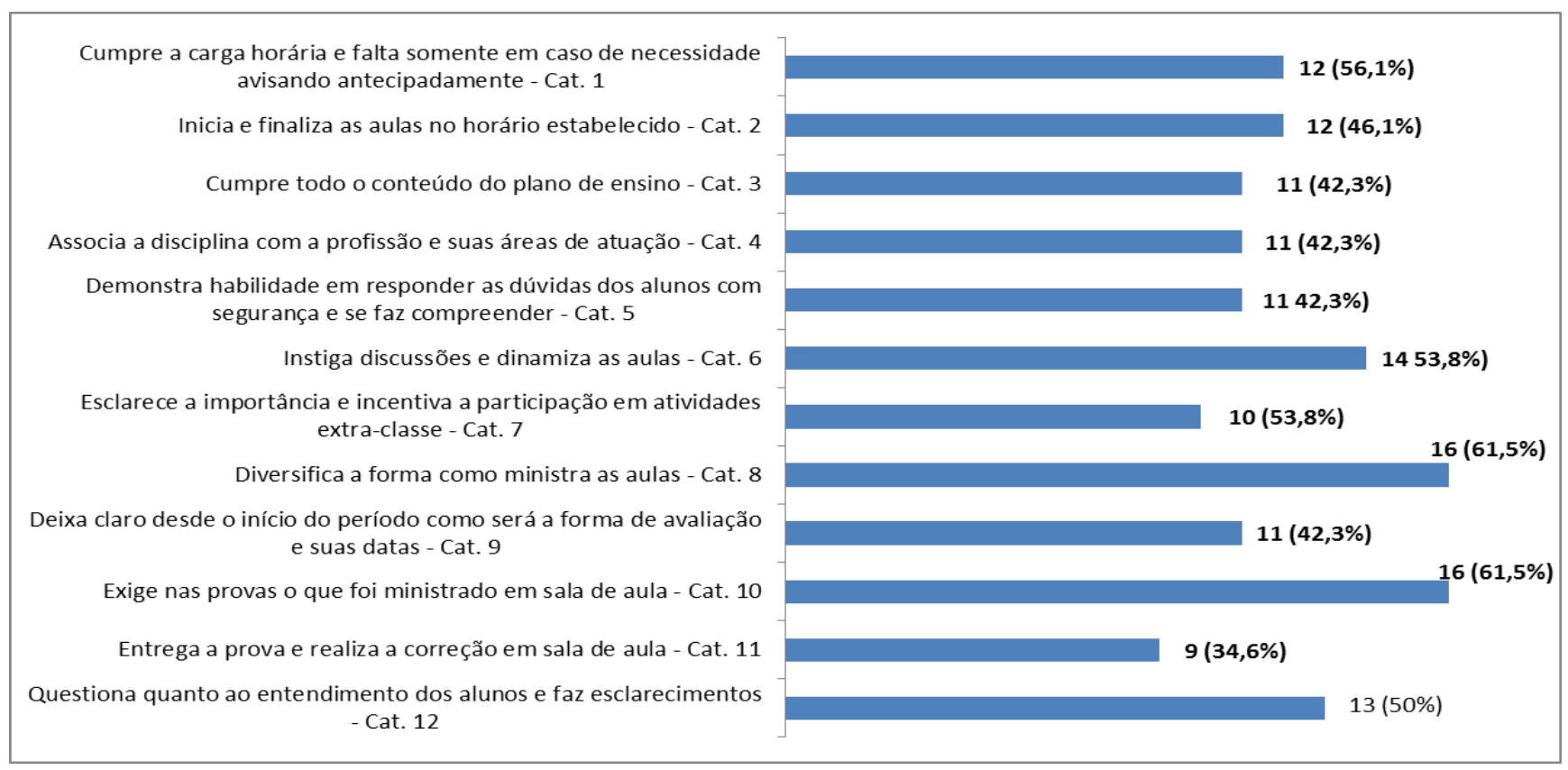


estabelecido. Cinco alunos citaram que além do professor começar e terminar a aula no horário, ele deve respeitar o intervalo, quando houver, e não deve estender a aula para além do horário. Somente dois alunos (sujeito 12 e 13) mencionaram que o professor deve chegar mais cedo para preparar os equipamentos que serão usados na aula.

Figura 1 - Distribuição das respostas mais frequentes dentro das 12 categorias gerais que emergiram das respostas dos estudantes $(n=26)$ em cada item do instrumento aplicado, outubro/2011. Legenda: Cat. = categoria .

Sobre a questão que se referiu ao alcance dos objetivos do plano de ensino da disciplina (categoria 3), a maioria dos estudantes (11) escreveu que o professor que alcança os objetivos do plano de ensino é aquele que cumpre todo o conteúdo. Esta interpretação não era esperada, já que se referiu ao conteúdo programático e não aos objetivos do plano de ensino. As falas abaixo descrevem essa interpretação:

"Se ele cumpre todas as matérias/temas que foram expostos no plano de ensino, se não pula partes ou deixa faltar conteúdo". (sujeito 7)

"[...] sendo que alguns casos é possível que seminários apresentados por alunos atinjam os objetivos também". (sujeito 6)

Cinco alunos mencionaram que o professor alcança os objetivos quando o aluno compreende o que o professor propõe, como observado nas falas abaixo:

“[...] não adianta dar todo conteúdo correndo e não ensinar direito, deve ensinar normal, mesmo que atrase um pouco, mas o objetivo é ensinar ao aluno e não mostrar todo o conteúdo da disciplina". (sujeito 12)

"Se eu consigo compreender a matéria, relacionar os conteúdos dados [...]". (sujeito 11)

"Avalio de acordo com os resultados obtidos no final da disciplina como aprendizado, interação e contextualização". (sujeito 16) 


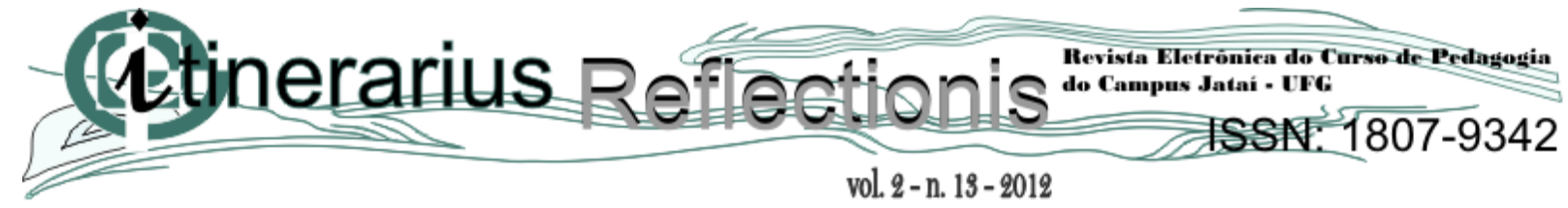

Somente seis alunos mencionaram que conferem os objetivos no plano de ensino para avaliar se o professor os alcançou.

Na pergunta sobre o estabelecimento de relação entre a disciplina e o curso (categoria 4), a maioria dos estudantes (11) interpretou que o professor que estabelece essa relação é aquele que associa a disciplina com a profissão e suas áreas de atuação, como pode ser exemplificado pela fala abaixo:

"O professor estabelecer uma relação entre a disciplina e o curso é tentar chegar o mais perto possível do que será útil para a futura profissão do acadêmico." (sujeito 9)

Ainda nessa pergunta, dez alunos mencionaram sobre o professor que mostra a importância da disciplina e a associa com o curso, conforme as falas abaixo:

"É buscar mostrar que a disciplina que ele administra é de fundamental importância para o determinado curso". (sujeito 10)

“[...] o professor não deve aplicar uma matéria para que os alunos fiquem se perguntando para que sirva esta matéria, e sim falar essa matéria é importantíssima para o curso". (sujeito 12)

"[...]. Houve, por exemplo, professor [...] que passou toda a disciplina utilizando modelos de bovinos, caprinos, equinos, sendo que seria perfeitamente possível utilizar modelos humanos e se adequar a um curso da área da saúde". (sujeito 20)

$\mathrm{Na}$ questão sobre o entendimento do estudante quanto ao professor que domina os conteúdos e tem didática ao ministrá-los (categoria 5), a maioria dos alunos (11) mencionou que esse professor é aquele que demonstra habilidade em responder as dúvidas dos alunos e que é compreendido.

Nesta questão, foi observado que alguns alunos mencionaram que esclarecer as dúvidas é de extrema importância, mesmo que não seja no momento, deixando claro que eles não cobram do professor respostas imediatas, mas observam se este vai atrás de informações para solucioná-las. Seguem algumas falas relacionadas: 


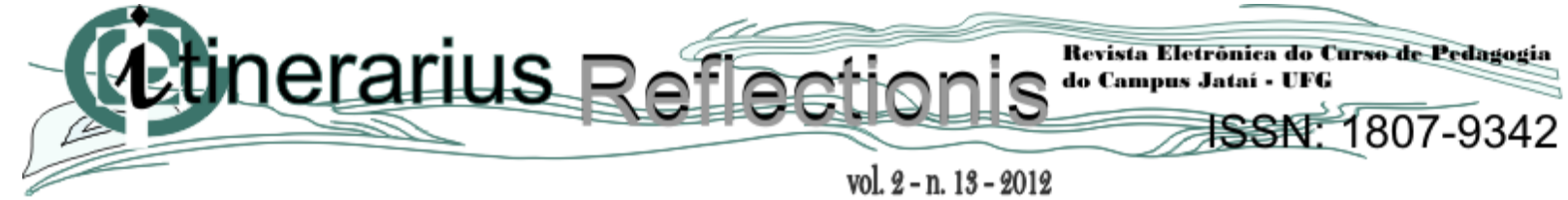

"Demonstrar domínio para mim não significa saber tudo sobre um assunto, mas saber onde obter todas as informações que necessita e assim, direcionar o aluno e, naturalmente, significa também possuir uma considerável bagagem de conhecimentos a cerca do assunto/disciplina em questão. Expor didaticamente significa saber situar o aluno dentro do assunto, dividindo o assunto em partes para ficar mais claro o assunto total". (sujeito 20)

"Quando mostra segurança durante as aulas e os explica de forma clara de se entender". (sujeito 15)

“[...] um professor que domina é aquele que, quando os alunos perguntam, ele não demonstra insegurança e sim responde com clareza ao aluno". (sujeito 12)

"Quando o professor possui domínio do conteúdo ele consegue sanar suas dúvidas, mesmo que seja em outro dia, mas o didático é quando boa parte dos alunos entende o que ele expos e consegue prender a atenção da turma com suas aulas". (sujeito 6)

Além de relacionar o domínio do conteúdo com a segurança demonstrada pelo professor, um aluno mencionou que a utilização de recursos como trabalhos em grupos ou seminários em excesso está relacionada com o não domínio do conteúdo:

“[...] professores (que dominam o conteúdo) não dão trabalhos em grupo e seminários em excesso porque, para mim, isso é coisa de professor que não sabe ou que não quer dar aula." (sujeito 13)

Outro aluno relacionou essa questão com a forma como o professor ministra a aula e sua disposição em explicar:

"[...] composição dos slides e a maneira e disposição para a explicação do conteúdo, clareza, fala e postura”. (sujeito 14)

Dois alunos mencionam que o domínio e a didática estão relacionados com a profundidade com que trata os conteúdos e a coerência entre o que é exposto nas aulas e o conteúdo dos livros, como demonstrado nas falas abaixo: 


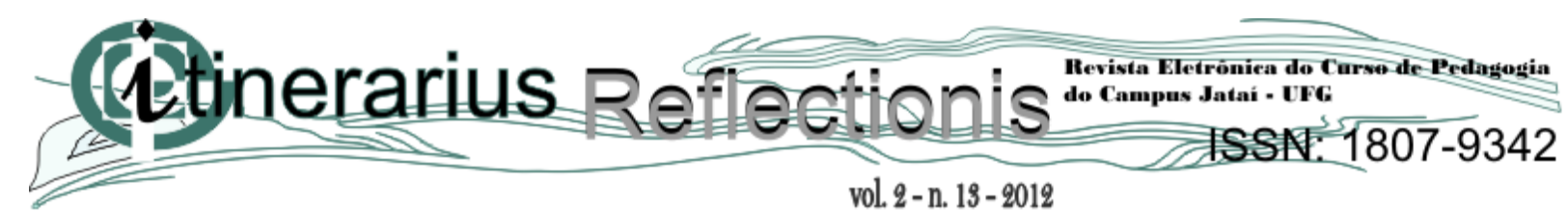

"Capacidade de ensinar com profundidade e didática a sua matéria abordada, sem que haja incoerência diante aula, perguntas e livros". (sujeito 22)

“[...] sua exposição é didática quando aborda de forma clara e com relativa profundidade o conteúdo". (sujeito 16)

Somente dois alunos mencionaram que observam a linguagem não verbal do professor:

\begin{abstract}
"O professor que não demonstra algum "tic", normalmente domina o conteúdo que administra". (sujeito 10)

"Sua postura diante dos alunos, domínio sobre a matéria, tom de voz, entrosamento com os alunos". (sujeito 26)
\end{abstract}

Quanto à pergunta sobre a mobilização do interesse e o estímulo à participação do aluno (categoria 6), a maioria dos estudantes (14) mencionou que o professor que mobiliza o interesse é aquela que instiga discussões e dinamiza as aulas, conforme os trechos abaixo:

"Aquele que consegue prender a atenção dos alunos e consegue despertar dúvidas e entendimento que os fazem questionar". (sujeito 15)

"É aquele professor que traz curiosidades, que deixa algo no ar como uma dúvida, estimulando o aluno a procurar sobre aquele assunto". (sujeito 10)

"Para mim é um professor que estimula os alunos a buscarem mais conhecimento do assunto e estimula a participação e interação do aluno com a aula". (sujeito 17)

"É aquele que em sua dinâmica de trabalho atrai os alunos, a fim de que esses busquem por conta própria informações a respeito da disciplina e seu uso prático". (sujeito 16)

O exposto acima nos faz refletir sobre a importância do professor como mediador do conhecimento, deixando o aluno construí-lo (SANTOS; LAROS, 2007).

Dois alunos mencionaram que professores que não reprimem perguntas são professores que conseguem mobilizar a participação dos alunos: 


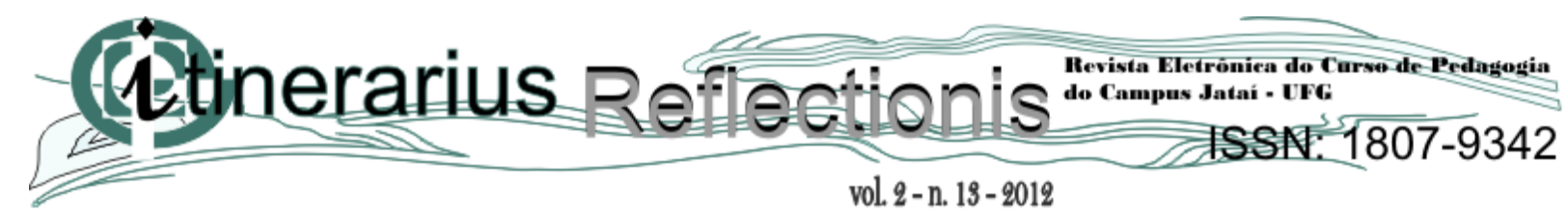

“[...] é um professor que não reprime perguntas ou respostas equivocadas, desde que elas sejam convenientes e pertinentes [...]". (sujeito 20)

"Professores abertos às perguntas, questionamento e críticas. Professores que têm segurança do conteúdo e deixam alunos perguntarem [...]". (sujeito 13)

Quanto à questão que se referiu ao professor que incentiva a participação dos alunos em atividades extraclasses (categoria 7), a maioria dos estudantes (10) mencionou que esse professor é aquele que esclarece a importância da participação em atividades extraclasse, conforme a fala a seguir:

"É quando o professor estimula a pesquisar sobre determinado assunto, ou participar de outras atividades fornecidas pela comunidade acadêmica (como ligas, grupos de estudos, cursos de extensão universitária etc)". (sujeito 20)

Para sete estudantes, o professor deve mostrar interesse em ajudar e convidar o aluno a participar de atividades extraclasses. Observamos que a maioria dos alunos não aprofundou nessa questão, apenas reafirmando que é importante que o professor incentive a participação.

Na pergunta sobre a utilização de metodologias diversificadas e instigadoras (categoria 8), 16 alunos mencionaram a importância do professor que diversifica a forma como ministra as aulas:

\footnotetext{
"Mudar a forma de ensino durante as diversas aulas do período, mudando a forma metódica de aulas [...] técnicas novas". (sujeito 15)

"[...] significa o uso de artifícios que não só datashow para proporcionar variabilidade de didática. Exemplo discussão de artigos, dinâmicas, rodas de conversa, para discutir práticas e conteúdos". (sujeito 14)
}

Nessa pergunta, dos 26 alunos, cinco encaram a pergunta como afirmação e apenas reforçaram a importância de utilizar metodologias diversificadas.

Um aluno citou a importância de diversificar os métodos de ensino-aprendizagem sem cometer exageros, como por exemplo, de seminários. 


\section{(1Etinerarius Reflectionis:}

Dois alunos citaram a importância de professores e alunos aprenderem juntos, conforme exemplificado abaixo:

“[...] onde aluno e professor aprendem juntos sempre sendo o professor a guia, aquela que orienta e delimita os assuntos e naturalmente, usar recursos audiovisuais, jogos, viagens outras formas de aprendizado, seminários". (sujeito 20)

Três alunos escreveram que não entenderam essa questão. (sujeitos 3, 4 e 12)

$\mathrm{Na}$ pergunta que se referiu ao professor que informa antecipadamente e de forma clara os critérios de avaliação (categoria 9), 11 alunos entenderam que esse professor é aquele que, desde o início do período, deixa claro como será a forma de avaliação e as datas das avaliações.

Oito alunos mencionaram a importância de disponibilizar por escrito os critérios de avaliação no plano de ensino:

"No primeiro dia de aula, explica o plano de ensino e informa a cada mudança. Em relação ao critério de avalição, acredito que seja necessário deixar claro as datas e as formas de avaliação". (sujeito 14)

Um aluno salientou que além de disponibilizar por escrito, o professor deve discutir com os alunos os critérios de suas avaliações:

"Quando expõe isso de forma clara no plano de ensino e discuti isso com os alunos". (sujeito 20)

Na questão que perguntou sobre o entendimento do aluno quanto à coerência do professor ao avaliar (categoria 10), 16 alunos responderam que o professor é coerente quando exige na prova o que foi ministrado em sala de aula:

"Quando cobra somente aquilo que foi ministrado e não incluindo assuntos paralelos relacionados". (sujeito 2) 


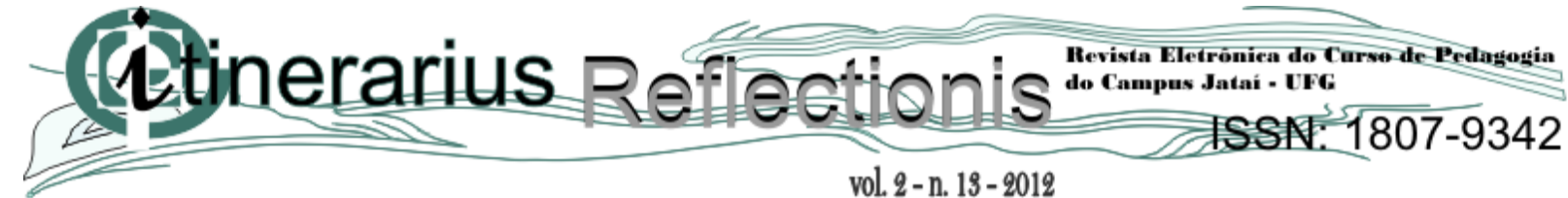

Em contrapartida, outro aluno acha que devem ser exploradas outras fontes de informação, como na fala abaixo:

"Quando o professor cobra não somente o conteúdo que ele expos em sala de aula, mas também o que se encontra nos conteúdos de suas referências bibliográficas". (sujeito 17)

Um aluno comentou que o professor "deve respeitar o que é escrito em síntese e não decorado e transcrito de livros e outros textos". (sujeito 6)

Seis alunos mencionaram a importância de o professor ser flexível e imparcial ao corrigir e dar notas às avaliações, como exemplificado nas falas abaixo:

“[...] não zerando uma questão completa por causa de fatores irrelevantes". (sujeito 22)

"Quando é proporcionado igualdade entre todos os acadêmicos". (sujeito 9)

Na questão sobre a devolução de avaliações (categoria 11), nove alunos relataram que entregar as provas e realizar a correção em sala de aula é o que é esperado do professor neste item:

"[...] pois, assim, é possível o aluno ver onde errou e assim indagar o professor caso não concorde". (sujeito 4)

"Pois é através das avaliações que percebemos o quanto que aprendemos e absorvemos os conteúdos das disciplinas". (sujeito 5)

"Entregar as avaliações dias antes das outras avaliações para que o aluno possa ver o que ele errou e possa corrigir esses erros antes das outras avaliações". (sujeito 6)

Nessa questão, oito alunos registraram que a devolução das provas é um direito do aluno e um dever do professor:

"Um direito nosso de receber, um dever do professor, pois precisamos estar cientes de como saímos nas avaliações". (sujeito 24) 


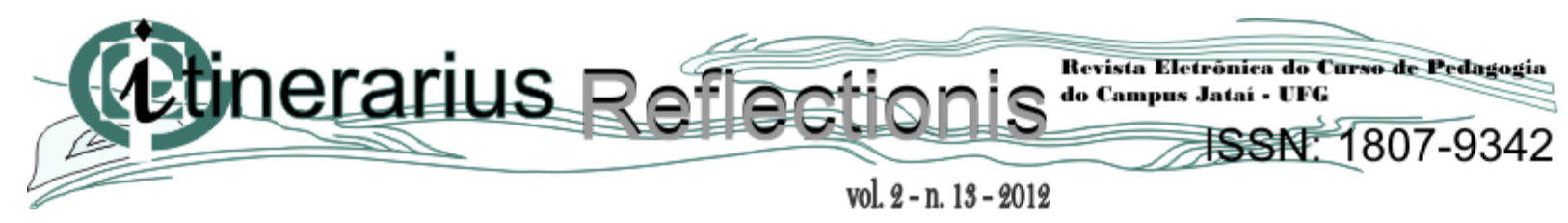

“[...] e que devolva todos os tipos de avalições". (sujeito 9)

Ainda nessa questão, seis alunos referiram que o professor não deve demorar em corrigir a prova e deve entregá-la antes da próxima prova:

"[...] tem professor que demora mais de meses para corrigir e devolver uma prova”. (sujeito 22)

Na pergunta que se referiu ao interesse do professor quanto à compreensão, desempenho e aprendizado dos alunos (categoria 12), 13 estudantes descreveram que é importante o professor questionar quanto ao entendimento do aluno e fazer esclarecimentos.

Nessa questão, cinco alunos relataram ser importante o professor respeitar as dificuldades e individualidades dos alunos:

"Tem dedicação, segurança ao aplicar sua disciplina respeito e atenção por aqueles que têm uma certa dificuldade na matéria e não isolar dos outros alunos". (sujeito 12)

“Quando ele respeita o tempo de aprendizagem de cada aluno". (sujeito 9)

Um aluno mencionou que o professor deveria utilizar várias formas de avaliação para verificar o aprendizado:

"Não dá valor apenas a nota do aluno, mas a sua participação e dá outras formas de avalição que não somente a prova escrita, porque sabe que há formas diferentes de demonstrar aprendizado". (sujeito 20)

Somente um aluno levantou a possibilidade de reflexão sobre o processo ensinoaprendizagem e as responsabilidades dos professores e dos alunos nesse processo:

"Nota que os alunos não estão com interesse, que as notas estão ruins e o que ele pode estar fazendo, se o problema é no modo com que ele está aplicando 


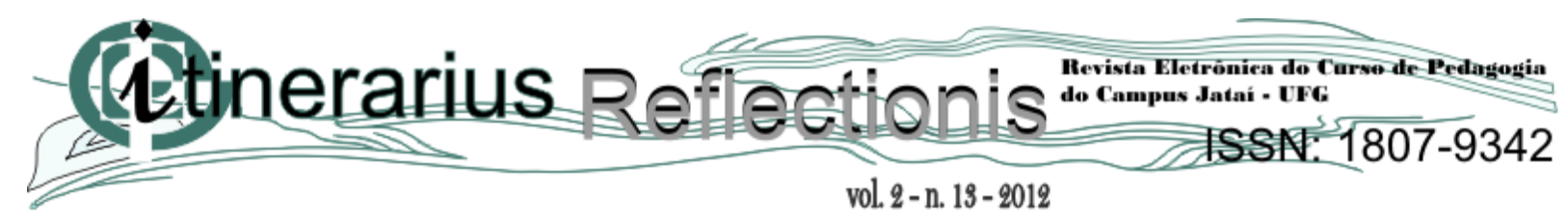

a disciplina ou se é com o interesse do aluno, o que ambos podem fazer para a melhoria do aprendizado". (sujeito 3 )

\section{Considerações finais}

Respondendo ao questionamento que nos moveu à pesquisa, acreditamos que os alunos de uma forma geral entendem as questões do instrumento de avaliação da UFG. Entretanto, seria necessária uma pesquisa mais criteriosa, abrangendo outras metodologias, para constatar o nível de entendimento das questões, até mesmo entre os alunos que as consideraram claras e de fácil entendimento.

Partindo do pressuposto que há entendimento das questões por parte dos alunos, se o professor recebe uma nota não esperada, pode ser que outros fatores estejam influenciando as notas dadas pelos alunos como, por exemplo, medo de represália, empatia pelo professor, desempenho na disciplina, entre outros. Assim, sugerimos que novos estudos sejam conduzidos nesta instituição abordando essas questões.

Em contato com as respostas obtidas no questionário aplicado foi possível perceber que a contribuição do aluno é maior quando se utiliza questões abertas, pois elas não expressam somente notas, mas também expectativas quanto às atividades docentes. Sabe-se que a instituição desse estudo permite em seu sistema que o aluno avalie o professor de forma discursiva. Porém esta avaliação discursiva parece não incentivada entre os alunos e muitos professores desconhecem sua existência.

Dentre as questões avaliadas, a que mais nos chamou a atenção foi a relacionada ao alcance dos objetivos do plano de ensino, porque a maioria dos alunos entendeu que o cumprimento de todo o conteúdo do plano corresponde ao alcance dos objetivos. Portanto, seria interessante que os professores expusessem de forma mais clara os objetivos propostos em cada disciplina de modo que os alunos consigam ao final do conteúdo identificar se os objetivos foram ou não atingidos. 


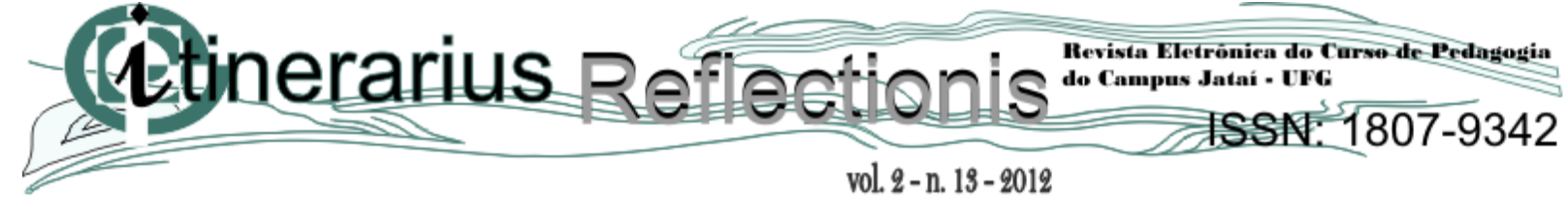

\section{REFERÊNCIAS}

BRADLEY, J. Methodological issues and practices in qualitative research. Library Quarterly, v. 63, n. 4, p. 431-49, 1993.

GRILLO, M.C. Qualidade no ensino superior: um referencial pedagógico de professores. Porto Alegre. Tese (Doutorado). Faculdade de Educação/PUC, RS, 1992.

KAPLAN, B.; DUCHON, D. Combining qualitative and quantitative methods in information systems research: a case study. MIS Quarterly, v. 12, n. 4, p. 571-86, 1988.

KURCGANT, P.; CIAMPONE, M.H.T.; FELLI, V.E.A. Avaliação de desempenho docente, discente e de resultados na disciplina administração em enfermagem nas escolas de enfermagem no Brasil. Rev Esc Enferm USP, v. 35, n. 4, p. 374-80, 2001.

MARTINS, J.; BICUDO, M.A.V. A idéia de fato e a de fenômeno. In: MARTINS, J.; BICUDO, M.A.V. A pesquisa qualitativa em psicologia. 2. ed. São Paulo: Moraes; 1994. p. 21-5.

MINAYO, M.C.S.; DESLANDES, S.F.; NETO, O.C.; GOMES, R. Pesquisa Social: Teoria, Método e Criatividade. 16. ed. Petrópolis: Vozes; 2000. p. 67-79.

RAMOS, M.G.; MORAES, R. Avaliação do desempenho de professores numa perspectiva qualitativa: contribuições para o desenvolvimento profissional de professores universitários. Disponível em: <http://www.rieoei.org/deloslectores/108Maurivan.pdf>. Acesso em: 08 nov. 2011.

SANTOS, L.F.B.P.; LAROS, J.A. Avaliação da prática pedagógica do professor de ensino superior. Estudos em Avaliação Educacional, v. 18, n. 36, p. 75-96, 2007.

SILVA, C.R.; GOBBI, B.C.; SIMÃO, A.A. O uso da análise de conteúdo como uma ferramenta para a pesquisa qualitativa: descrição e aplicação do método. Organ Rurais Agroind, v. 7, n. 1, p. 70-81, 2005.

STRASSBURG, U.M.; MOREIRA, D.A. Avaliação de Desempenho de Professores pelo Aluno: uma experiência desenvolvida junto a um curso superior de Contabilidade. Ciências Sociais em Perspectiva, v. 1, n. 1, p. 1-21, 2002. 

Etinerarius Refoctionis: 20

vol. 2-n. 13 - 2012

ISSN: 1807-9342 